\title{
EL ASEDIO A LA CASA: UN ESTUDIO DEL DECORADO EN LA NOCHE DE LOS ASESINOS
}

José Triana (n. 1932) es uno de los autores teatrales más destacados de Cuba. Entre sus obras más conocidas figuran El general hablará de teogonía, Medea en el espejo, La muerte del Ñeque y La visita del ángel.

La noche de los asesinos (1964) es sin duda su mejor pieza teatral y una de las más sobresalientes de la escena hispanoamericana contemporánea. Ha sido representada en los Estados Unidos, Europa y los países de la Unión Soviética. Es también una obra que ha suscitado el interés de la crítica, que le ha consagrado estudios importantes ${ }^{1}$.

' Jean Franco pone de relieve la afinidad de Triana con algunos cultivadores destacados de otros géneros hispanoamericanos: "The problems raised in La noche de los asesinos are ... similar to those raised in the contemporary poetry and the novel. The two acts of the play centre on the family and on society. The play reflects both the conflict between spontaneity and order and the tragic progress of human relations in which freedom invariably gives way to the killing of the other. Triana's choice of theme, his demonstration of the deadening effect of routine, of set patterns ... bring him close to César Vallejo, Neruda and Octavio Paz - all of whom have touched on this theme in their poetry. And we shall find that the attack on dead order was also an important feature of prose writing», Spanish American Literature (Cambridge, 1969), p. 299.

Frank Dauster estudia la obra de Triana conjuntamente con las otras del mismo autor. Señala semejanzas con la pieza de Jean Genet las criadas y con la del argentino Osvaldo Dragún Historias para ser contadas, en lo que atañe a los cambios rápidos de papeles. "The Game of Chance: The Theater of José Triana», Dramatists in Revolt (Austin, 1976), pp. 167-189.

Anne C. Murch hace un estudio comparado del rito en Las criadas de Genet, Chamber Music de Arthur Kopit y la pieza de Triana. «Genet, Triana, Kopit: Ritual as Danse Macabre», Modern Drama, vol. XV, 4 (March 1973) 369-381.

Kirsten Nigro pone de relieve los elementos estructurales y técnicos que caracterizan esta obra cuando se traduce en representación escénica. "La noche de los asesinos: Playscript and Stage Enactment», Latin American Theatre Review, vol. 11, 1 (Fall 1977), 45-57.

Carlos Solórzano le consagra unas breves notas después de haberla visto por 
En breve, he aquí la historia de la pieza. Lalo, Cuca y Beba, tres hermanos, representan el juego del asesinato de sus padres. Vislumbra que en sus frecuentes desdoblamientos este juego ha sido repetido varias veces. Lalo ha cometido el parricidio y es sometido a un interrogatorio por la Policía y el fiscal. Al final del juego, Beba dice que ahora le toca a ella; es decir, el juego va a volver a empezar. La obra se desarrolla en un plano subjetivo. Lalo irrumpe en el cuarto cargado de tensión psíquica. Los personajes adoptan varias personalidades sin que se verifiquen cambios visibles en el decorado.

Los tres son seres oprimidos, reducidos a la condición de objetos. Hacen pensar en la dicho por Paulo Freire en su libro sobre la opresión, Pedagogy of the Oppressed: "They have been destroyed precisely because their situation has reduced them to things. In order to regain their humanity they must cease to be things and fight as men ${ }^{2}$. Pero les falta valor para sobreponerse a su estado de completa dependencia. Acierta Kirsten Nigro cuando señala el miedo como una de las causas de su estado de impotencia: «The motive of fear is recurrent throughout the play and emphasizes the fact that the characters are not so much slaves as they are self-enslaved. Thus the demons to be exorcised are the private ones who dwell in the recesses of the mind, where they grow and fester» ${ }^{3}$. Estos «demonios privados» de los tres personajes hacen que el drama se desarrolle al nivel del subconsciente, como se tratará de demostrar más adelante.

Cabe aquí hacer una pausa para destacar lo que entendemos por obra teatral, para luego poder pasar al estudio del decorado en La noche de los asesinos. El teatro es comunicación. El autor no escribe principalmente para un lector. Claro está, los actores, técnicos y director tienen que leer la obra para poderla representar; pero el destinatario principal es el espectador. Este recibe informaciones no sólo por medio de la pa-

primera vez en Cuba en el Concurso Anual de Teatro. Testimonios teatrales de México (México, 1973), pp. 231-233.

Matías Montes Huidobro, en su análisis de la idiosincrasia cubana vista a través del teatro, se interesa por el aspecto social y psicológico de la obra Persona, vida y máscara en el teatro cubano (Miami, 1973), pp. 413-427.

Julio Ortega destaca diversos temas de la pieza y observa, entre otras cosas, que «lo que justifica el crimen, o al menos el rito de su posibilidad, es la opresión más vasta y secreta que simbolizan los padres como rostros de una sociedad que impone el fracaso de los individuos, de un mundo corroído por la sumisión alienada». "La noche de los asesinos», Cuadernos Americanos, 164 (mayo-junio 1969), 264.

2 Paulo Freire, Pedagogy of the Oppressed (New York, 1970), p. 55.

${ }^{3}$ Nigro, p. 49. 
labra, sino por varios-sistemas de signos. Al representarse el texto primero cambia. De teatro en potencia se convierte en teatro en presencia. A los signos del primer texto se añaden otros. Estudiada detenidamente, se nota que la obra consta de una compleja red de signos que no existen separadamente, sino que reciben otros niveles de significado al entrecruzarse con otros.

Los signos del decorado constituyen uno de los muchos sistemas de signos que integran una pieza, y que sólo por razones de espacio y de tiempo no se estudiarán en este artículo. Nos limitaremos, por tanto, a analizar los signos del decorado.

En el curso de este estudio se identificarán tres categorías de signos. Un objeto es signo de objeto cuando indica lo que muestra (un cenicero puede significar que está allí para recoger las cenizas del personaje que fuma). Sin embargo, a este significado primario se le puede asignar otro, y es entonces signo de signo (el cenicero está lleno de colillas, indicando que el personaje fuma mucho porque está nervioso). Hay también objetos que alcanzan categoría de símbolos. En La gringa de Florencio Sánchez, el ombú, el árbol nativo de la pampa argentina, es símbolo del modo de vivir del criollo. Y como símbolos pueden hasta dar el título a una obra, v. gr.: El cepillo de dientes del chileno Jorge Díaz.

En este estudio intentaremos examinar el sistema de signos escénicos del decorado. Por decorado entendemos el conjunto de escenografía y objetos de utillería, que tiene como función la de representar un lugar determinado y crear un ambiente.

En La noche de los asesinos hay dos decorados: uno que se presenta perceptiblemente y otro sugerido. El punto de partida en una obra de teatro es siempre un espacio escénico, es decir, un lugar en donde se desenvuelve la acción y en el que se mueven los actores. Este puede o no cambiar o ser reemplazado por otro durante la representación. En $L a$ noche de los asesinos permanece igual hasta el final. Sin embargo, además de este espacio, existen otros sugeridos por los personajes y de los cuales los espectadores, por tácito acuerdo, tienen que crearse una imagen visual.

Gráficamente, y en su esquema sígnico, la obra se descompone en los siguientes espacios: un sótano o el último cuarto-desván, la casa, una Estación de Policía y un Tribunal: 


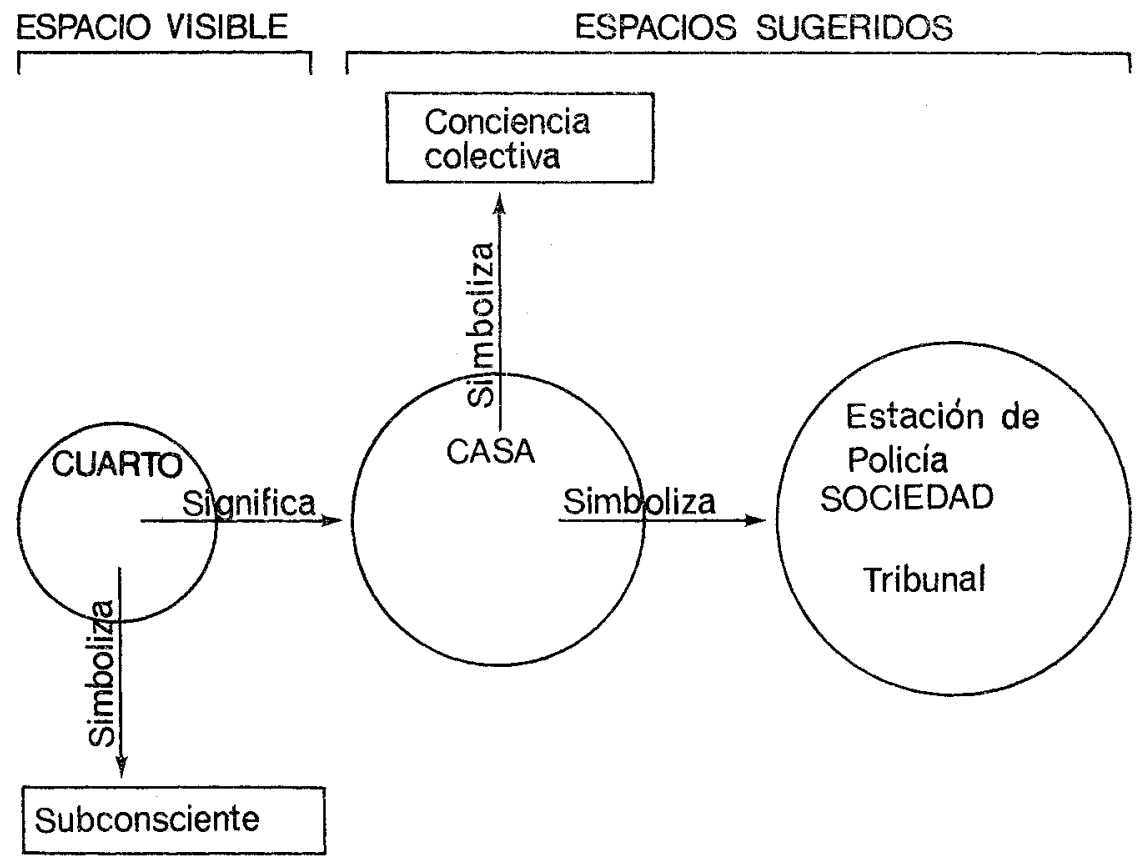

En la obra no hay cambios escénicos, es decir, se sigue «viendo» el cuarto. Sin embargo, en el múltiple juego de planos de realidad que caracteriza la pieza, el cuarto será signo de la casa y ésta de la sociedad total. Los objetos contenidos en los tres espacios comunican categorías sígnicas: la de signos de objetos, de signos de signos y de símbolos.

\section{Decorado Visible}

a) El cuarto

Los signos escénicos con que comienza la obra muestran un lugar empolvado y descuidado de la casa:

Un sótano o el último cuarto-desván. Una mesa, tres sillas, alfombras raídas, cortinas sucias con grandes parches de telas floreadas, floreros, una campanilla, un cuchillo y algunos objetos ya en desuso, arrinconados, junto a la escoba y el plumero ${ }^{4}$.

${ }^{4}$ José Triana, La noche de los asesinos (La Habana, 1965), p. IV. De aquí en adelante se indicará el número de la página al lado de la cita de este libro. 
Fijémonos en las palabras sótano o desván. Es evidente que Triana no estaba pensando en un cuarto cualquiera de la casa. Y si el director escoge el «sótano», es importante que tenga presente que no puede ser un sótano al estilo norteamericano, sino un lugar apartado, empolvado, poco visitado por la familia.

Decidimos estudiar el decorado en la pieza de Triana no sólo por haberse pasado por alto su importancia en la crítica, sino también por un error de traducción. En una ocasión el sótano o el desván se tradujo «a room» ${ }^{5}$. Nos pareció que estaban completamente despistados. El escenario no es un cuarto cualquiera de la casa, sino un lugar preciso, un lugar apartado de la casa.

Por lo general, el sótano o el desván es un lugar marginado de las casas en que se guardan objetos que la casa rechaza. Como habitación secundaria es un sitio poco frecuentado en que los niños suelen encerrarse para aislarse del mundo de los mayores. Allí pueden fantasear, adoptar otras personalidades y encarnar a sus padres en sus momentos de tiranía. Es un lugar mágico, en que pueden dar rienda suelta a su imaginación.

Ahora bien: el haber escogido este escenario no es un hecho gratuito. El cuarto significa la marginalidad existencial de los tres jóvenes. Además, como lugar usualmente frecuentado por los niños para sus juegos, connota que estos jóvenes (el autor anota que son adultos) siguen siendo tratados como niños y no han podido madurar psicológicamente.

La «noche» del título de la obra, que sugiere la oscuridad del yo profundo; el cuarto con su contenido incoherente, la obsesionante insistencia en objetos aparentemente banales, los desdoblamientos de personalidad, el juego pueril que contrasta con la edad de los jóvenes, no dejan duda sobre el nivel subconsciente y alucinante del drama. Este es el plano más oculto de la obra y es fácil que no sea captado por el receptor, por lo ambiguo y oscuro de sus componentes sígnicos. Se podría argüir que la pieza de Triana no está presentada con una explícita estructura que revele el estado alucinante de los personajes. Sin embargo, en el teatro moderno, y en particular en el teatro del absurdo, con el cual La noche de los asesinos tiene puntos de contacto, el deslinde entre estados conscientes y subconscientes no se manifiesta a través de la estructura. Martin Esslin, en su ensayo «The Theatre of the Absurd Reconsidered», afirma:

What the absurdists have done is liberate this kind of internal reality from the necessity of having to emerge from an external plot

'5 The Criminals, en The Drama Review (Winter 1970), 104-129. 
situation with neat transitions from reality to dream, from nature to hallucinations ${ }^{6}$.

Es importante subrayar el singular estado psíquico de los personajes y la estrecha relación psicológica entre sí. Aunque es Lalo el personajeeje, los tres funcionan en el mismo plano subjetivo y se sugiere que se turnan en el rol protagónico del parricida. En efecto, la obra se parece a un psicodrama de la moderna psicoterapia, en el cual los enfermos son los protagonistas del drama que ellos mismos crean. En una situación psicodramática todo pasa en el presente. Lo mismo ocurre en La noche de los asesinos. También comunes a los dos tipos de drama son los frecuentes desdoblamientos (los «role reversings» que prescribió el padre del psicodrama, Jacob Levi Moreno).

La «puerta» sirve para comunicar el significante cuarto-subconsciencia. La obra empieza con la orden de Lalo, «cierra esa puerta». Al cerrarse ésta, se excluye la conciencia y se dejan en libertad los deseos reprimidos. A veces el mundo del subconsciente asusta a los hermanos. Beba quiere dejar el cuarto porque la aterroriza la verdad de ese mundo y sus posibles consecuencias: «Cuca y Lalo intentan detenerla, pero ella llega hasta la puerta..., cae llorando junto a la puerta» (p. 43). Lalo, al final del primer acto, manda abrirla. Necesita un descanso después del esfuerzo agotador de su psique. El segundo acto comienza con la orden de cerrar la puerta, y en el desenlace de la pieza Lalo otra vez pide que la abran. La puerta, por tanto, significa el cerrarse y abrirse del mundo subconsciente. Se cierra cuando se quiere excluir la conciencia (ésta es incompatible con ese mundo por haber sido moldeada por la sociedad). Se abre cuando el drama interior se hace insoportable.

En un plano menos profundo, el cuarto es también signo de signo cuando representa la casa. En el múltiple juego, los tres protagonistas representan supuestas situaciones familiares que han tenido lugar en la casa.

Resumiendo su composición sígnica, el cuarto es signo de objeto (una habitación), signo de signo (significa la casa) y símbolo (el subconsciente de los tres) ${ }^{7}$.

- Reflections. Essays on Modern Theatre (Garden City, 1969), p. 187.

${ }^{7}$ El drama interior del subconsciente aparece en otras obras del teatro hispanoamericano. En el plano de pesadilla se desarrolla Los invasores de Egon Wolff. También en una atmósfera alucinante se despliegan sentimientos recónditos del subconsciente en La señora en su balcón de Elena Garro, Las sobras para el gusano de Franklin Domínguez. Véase nuestro estudio «La escenificación del fluir psíquico 


\section{b) Objetos de utilería}

Los objetos visibles y los sugeridos que contienen los tres espacios de nuestro gráfico comunican las tres categorías sígnicas. Muy temprano en la obra se observa la obsesión de los padres (representados por los hijos) por el orden y la limpieza de los objetos de la casa:

CucA: Hay que arreglar esta casa. (Quita un cenicero de la silla y lo pone sobre la mesa.)

Lalo (Autoritario): Vuelve a poner el cenicero en su sitio.

CUCA: El cenicero debe estar en la mesa y no en la silla.

Lalo (Coge el cenicero y lo pone otra vez en la silla): Yo sé lo que hago. (Coge el florero y lo pone en el suelo.) En esta casa el cenicero debe estar encima de una silla y el florero en el suelo (pp. 4-5).

La disputa se repite una y otra vez en la obra y otros objetos cambian de posición, trasladados de un sitio para otro.

Lalo, temporalmente fuera del juego, reconoce que la obsesión por los objetos de la casa, que ellos inconscientemente reproducen en su drama, es absurda:

LALO: ¿Qué importa esta casa, qué importan estos muebles si nosotros no somos nada, si nosotros vamos y venimos por ella y entre ellos igual que un cenicero, un florero o un cuchillo flotante? (p. 21).

Los jóvenes, como las cosas, no tienen vida propia; son manejados por la voluntad y al antojo de sus padres.

Un objeto clave es el cuchillo. De signo de objeto (una cosa que corta) alcanza la categoría de signo de signo (un arma que puede matar) y la de símbolo (de la libertad después de eliminar a los opresores). E1 cuchillo es el único objeto que los jóvenes pueden manejar independientemente de la voluntad de sus padres. Es como el fuego en la obra de otro latinoamericano, René Marqués, Los soles truncos, el cual puede más que la insensible autoridad de la sociedad.

en el teatro hispanoamericano», Aspectos del teatro moderno hispanoamericano (Bogotá, 1975), pp. 71-79. 


\section{DECORADO SUGERIDO}

Además del decorado que aparece de manera perceptible, hay espacios y objetos del teatro que no se muestran de un modo visible y que el espectador tiene que suplir con su imaginación, conjeturando su proyección escénica. En La noche de los asesinos los jóvenes actúan como si estuvieran en la Casa, luego en una Estación de Policía y finalmente en un Tribunal. Algunos de los objetos visibles que ellos utilizan en su juego (el cenicero, las sillas, etc.) y las frecuentes referencias a la casa crean una imagen visual de ésta suficientemente clara. Espacialmente, hablando, además, el cuarto es parte de la casa y por eso la transposición es más fácil. En el caso de los otros espacios, el espectador recibe la imagen sobre todo a través de la mímica y los signos auditivos.

\section{a) La casa}

La casa, sea como ambiente estrechamente asociado con el comportamiento y la psique de los personajes, sea como símbolo, aparece en muchas obras universales. A título de ejemplo, basta recordar en la prosa norteamericana «A Rose for Emily» de William Faulkner, «The Liar» de Henry James, «The Fall of the House of Usher» de Edgar Allan Poe y The House of the Seven Gables de Nathaniel Hawthorne. En la cuentística hispanoamericana no se puede menos de mencionar «La casa tomada» de Julio Cortázar. En el teatro, por la necesidad de limitar el radio de acción, las paredes domésticas son el espacio favorito. La casa alcanza varios grados de significación en unas piezas hispanoamericanas. En Los soles truncos de René Marqués, por ejemplo, la casa es un verdadero personaje que, como las dueñas, ha envejecido y sufrido la penuria y el inexorable pasar del tiempo y al fin muere con ellas en el incendio final.

En $L a$ noche de los asesinos la casa es lingüística y escénicamente la imagen central. Es el espacio maldito. Allí se deformó la realidad de los jóvenes. En el interminable drama de su subconsciencia, la casa es el blanco a que se apunta. Toda la obra es un asedio a la casa. Como signo de signo, la casa, por lo general, es el refugio de la familia. Irónicamente, en la obra de Triana se nos va comunicando como símbolo de opresión.

Ya hemos dicho que el cuarto en su desordenada disposición es símbolo del subconsciente; la casa, en cambio, en su orden establecido por los gustos y las normas de la sociedad (representada por los padres), se 
nos proyecta como símbolo de la conciencia colectiva que los jóvenes odian. La odian porque los ha hecho inútiles, psicológicamente deformes. Moldeada por la sociedad, ella desnaturaliza y desfigura los sentimientos más puros. Condenado a no ser lo que quiere ser, Lalo achaca la culpa a los padres:

Lalo: Papá y mamá no consienten estas cosas. Creen que lo que pienso y quiero hacer es algo que está fuera de toda lógica. Quieren que todo permanezca inmóvil, que nada se mueva de su sitio (p. 20).

Una vez Lalo quiso reformar el orden de la casa, pero los padres se le opusieron:

Cuca (Como la madre): Un día se le metió entre ceja y ceja que debíamos arreglar la casa a su antojo... Yo, al oír aquel disparate, me opuse terminantemente. Su padre puso el grito en el cielo. Pero ¿qué cosa es eso? Ay, usted no se imagina... El cenicero encima de la silla. El florero en el suelo. ¡Qué horror! Y luego se ponía a cantar a todo meter, corriendo por toda la casa: "La sala no es la sala. La sala es la cocina» (pp. 95-96).

Esta canción se canturrea también en el curso de la obra subrayando el deseo de cambiar el orden fijo de las cosas. Lalo era el joven idealista que creía poder reformar la sociedad desde adentro sin destruir su estructura básica. No lo logra porque los que mandan no lo dejan. Más tarde reconoce que es menester destruir antes para luego crear un nuevo orden. Siempre dentro del juego, Lalo entonces se convierte simbólicamente en el revolucionario que aboga por la lucha y la violencia. Cree que hay que destruir la conciencia colectiva para poder recobrar la libertad y para que los seres marginados se integren a la nueva sociedad: «Hay que tumbar esta casa», grita al colmo de la desesperación (p. 109). Es la revolución de los «seres-objetos» contra «la casa» que los aniquila.

Por lo que hemos dicho sobre el signo de la casa, ésta, como decorado sugerido, es de suma importancia dentro de la obra. Es el símbolo escénico clave para la comunicación del mensaje del emisor-creador.

\section{b) Otros escenarios sugeridos}

Además de la casa hay otros escenarios que se sugieren por medio de referencias, por la mímica, los signos auditivos (efectos sonoros) y los visuales (expresión corporal). En emisión simultánea, ellos proyectan el signo escénico de otro escenario: 
La escena, a partir de este momento, debe adquirir una dimensión extraña. Los elementos que se emplean en ella son: los sonidos vocales, los golpes sobre la mesa y el taconeo acompasado...

Cuca (Dictando automáticamente): En el local de esta Estación de Policía, y siendo...

BEBA (Moviendo las manos sobre la mesa repite automáticamente): Tac-tac-tac-tac. Tac-tac-tac-tac. Tac-tac-tac-tac (p. 72).

No cabe duda que al espectador no le hacen falta detalles realistas para captar el significado de los signos que le comunican los actores. Estamos en una Estación de Policía y se está redactando el acta del crimen. El tecleo enervante de la máquina de escribir, que no se ve, adquiere, sin embargo, el significante de automatismo e insensibilidad burocrática ${ }^{8}$.

Luego, el solo mover de una campanilla nos traslada a otro decorado, el Tribunal. El discurso dramático suple lo demás:

BeBA (Como un juez): Ruego al público que mantenga la debida compostura y silencio, o de lo contrario tendré que desalojar la sala y continuar las sesiones a puertas cerradas. (A Cuca.) Tiene la palabra el señor fiscal (p. 76).

Las referencias al público y a la sala amplían nuestra visión del espacio en que se está juzgando a Lalo, acusado de asesinato.

Estos dos ejemplos de escenarios sugeridos hacen patente la necesidad de valerse de los signos escénicos espacio-temporales inmersos en el diálogo para suplir lo que no se ve en el tablado y completar las imágenes que las acotaciones del autor sólo parcialmente proyectan.

\section{CONCLUSIONES}

En nuestro estudio del decorado de La noche de los asesinos hemos observado que aunque parezca que el dispositivo escénico visual (el cuar-

${ }^{8}$ Marcela del Río pone de manifiesto la deshumanización de la justicia: «Cuando Lalo se enfrenta a la justicia (uno de los inventos de que más se enorgullece la humanidad), ¿qué encuentra? Que la justicia se ha convertido en una rutina infamante que juzga el 'cómo' del hecho, pero nunca el 'por qué'. Y cuando responde 'los maté porque quería vivir', la justicia se desconcierta, ella preguntaba 'como los mató' y solamente eso, y no puede comprender que 'la casa entera, todo, todo' le exigía ese acto heroico». "La noche de los asesinos», Revista de Bellas Artes, núm. 18 (noviembre-diciembre 1967), 85-88. 
to último de la casa) no cambia a través de la pieza, en el plano imagi nativo, y por medio de signos de ambos textos, se transforma en tres dis tintos decorados: la Casa, la Estación de Policía y el Tribunal. En el curso de la fábula dramática los objetos alcanzan distintas categorías sígnicas.

El examen sistemático de todos los aspectos de una obra teatral (y no sólo el linguístico) es una necesidad reconocida por todos los críticos modernos de teatro. Del cuadro que Tadeusz Kowzan ha elaborado ${ }^{9}$ se deduce que el decorado es sólo uno de los trece sistemas de signos de que se compone una obra. Creemos, sin embargo, que en La noche de los asesinos es uno de los más importantes porque coadyuva sustancialmente a la comunicación del mensaje y pone de realce la alta calidad técnica y artística del teatro de José Triana.

Partiendo de un escenario y una decoración corpórea mínimos y articulando significados a distintos niveles (el del subconsciente, de la familia y de la sociedad) nos ha dado una visión aterradora de un mundo anquilosado y aplastante. El decorado en la obra de Triana no está separado de la acción y no tiene sólo una función denotativa; al contrario, se ajusta perfectamente a todos los otros sistemas de signos en una simbiosis escénica magistralmente acabada. Es esto lo que hace de La noche de los asesinos una de las mejores piezas teatrales del teatro hispanoamericano contemporáneo.

University of Toronto,

ERminio G. Neglia

Toronto, Canada.

9 Tadeusz Kowzan, «E1 signo en el teatro. Introducción a la semiología del arte del espectáculo», El teatro y su crisis actual (Monte Avila, 1969). Los otros sistemas son la palabra, el tono, la mímica, el gesto, el movimiento del actor, el maquillaje, el peinado, el traje, el accesorio, la iluminación, la música y el sonido. 
